\title{
Os medicamentos como uma questão estratégica para a viabilidade do Sistema Único de Saúde
}

\author{
I ${ }^{1}$ Marilena Cordeiro Dias Villela Corrêa, 2 Paulo Henrique Almeida Rodrigues, \\ ${ }^{3}$ Rosângela Caetano I
}

\begin{abstract}
${ }^{1}$ Instituto de Medicina Social, Universidade do Estado do Rio de Janeiro. Rio de Janeiro-RJ, Brasil (correamarilena@gmail.com). ORCID: 0000-0003-3908-8073

${ }^{2}$ Instituto de Medicina Social, Universidade do Estado do Rio de Janeiro. Rio de Janeiro-RJ, Brasil (pharodrigues@gmail.com). ORCID: 0000-0002-3159-6711

${ }^{3}$ Instituto de Medicina Social, Universidade do Estado do Rio de Janeiro. Rio de Janeiro-RJ, Brasil (caetano.r@gmail.com). ORCID: 0000-0003-1480-2453.
\end{abstract}

DOI: http://dx.doi.org/10.1590/S0103-73312018280101

Segundo a última Conta-Satélite de Saúde, as despesas com o consumo final de bens e serviços de saúde em 2015 corresponderam a 9,1\%\% do Produto Interno Bruto nacional ( $\mathrm{R} \$ 546$ bilhões). Desse total, o consumo de serviços respondeu por $79,2 \%$ e o de medicamentos a $19,0 \%$, mas houve queda da participação destes últimos entre 2010 (22,4\%) e 2015 (IBGE, 2017). Esses dados apontam o setor saúde como importante mercado para produtos e serviços no Brasil, destacando-se que, quando se consideram as despesas com medicamentos, o consumo das famílias é maior que o do governo.

Outros números que reforçam a importância do medicamento no cenário nacional provêm da Associação da Indústria Farmacêutica de Pesquisa (Interfarma). Com um mercado estimado em US\$1,4 trilhão para 2020, o Brasil situa-se entre os dez maiores consumidores de produtos farmacêuticos do mundo. Em cinco anos, o país passou de $10^{\circ}$ para o $7^{\circ}$ mercado mundial, com previsão de atingir a $5^{a}$ posição mundial na virada desta década. Em termos de faturamento anual, o mercado farmacêutico brasileiro girou em torno de R $\$ 63$ bilhões em 2015, sendo $\mathrm{R} \$ 11,8$ bilhões (18,7\%) referentes ao mercado público (INTERFARMA, 2016). 
Em todo mundo, a questão dos medicamentos e tecnologias farmacêuticas, especialmente as condições do acesso da população, do seu uso racional e de sua qualidade, são aspectos decisivos para o bom funcionamento das políticas públicas de saúde. Isto também se faz presente no Brasil, onde o Sistema Único de Saúde (SUS) se propõe a ser um sistema universal de saúde, garantindo acesso universal, integral e equânime à população. Entretanto, na conjuntura em que vivemos, vem crescendo a vulnerabilidade do país em relação a esta questão.

Desde o início dos anos 1990, o país vem padecendo, de um lado, de crescente dependência tecnológica e de importação, com tendência à elevação dos déficits na balança comercial de fármacos e produtos acabados e, de outro, de aumento da vulnerabilidade do ponto de vista sanitário e social, devido à não garantia de insumos e medicamentos essenciais, que decorre da própria situação de dependência. Atualmente, $90 \%$ das necessidades do setor são supridas por importações, segundo a Associação Brasileira da Indústria Farmoquímica e de Insumos Farmacêuticos (Abiquifi), segundo Mitidieri et al. (2015).

A queda da produção interna dos farmoquímicos, desde que foram levantadas as medidas protecionistas que prevaleciam a partirde 1941, tem aumentado a dependência das importações, como mostrado no estudo de Rodrigues e colaboradores disponível nesta publicação ("A evolução recente indústria farmacêutica brasileira nos limites da subordinação econômica”) Essa queda tem redundado na falta de vários produtos e insumos essenciais. Um exemplo crítico é o desabastecimento de medicamentos como a benzilpenicilina (e também das penicilinas procaína e cristalina), fármacos de primeira escolha para o tratamento da sífilis e sífilis congênita. Este medicamento tem sido objeto de faltas recorrentes no mercado brasileiro desde 2015 (BRASIL, 2015; 2016), constituindo situação de preocupação epidemiológica crescente. Infelizmente, não é situação isolada ou excepcional. O combate a diversas doenças emergentes e reemergentes, assim como a doenças crônico-degenerativas e a novas ameaças sanitárias, fica, dessa forma, fragilizado.

Desde a promulgação da Lei no. 9.279/1996 (BRASIL, 1996), mais conhecida como "lei de patentes" (KORNIS et al., 2008), vem sendo limitada a capacidade de o país desenvolver competência em termos da produção e do desenvolvimento científico e tecnológico na área (BRASIL, 2011; COSTA et al., 2014). A Política Nacional de Medicamentos de 1998 contém diretrizes relativas à produção e à 
pesquisa (BRASIL, 1998), entre outras, mas não produziu mudanças significativas nesse cenário de vulnerabilidade.

No campo da produção, embora as três iniciativas mais importantes desde então - a produção de genéricos, a partir da promulgação da Lei n ${ }^{\circ} 9.787$ (BRASIL, 1999), a "quebra de patentes" para a produção interna de antirretrovirais (culminando no licenciamento compulsório do efavirenz em 2007) e as parcerias de desenvolvimento produtivo (gestadas a partir de 2008 e com foco sobretudo em medicamentos da atenção à média e alta complexidade) — tenham contribuído para a redução de preços nas compras pelo sistema público e no gasto das famílias, não foram capazes de alterar, de forma substancial, o quadro geral de dependência tecnológica e comercial.

Ao mesmo tempo, houve avanços importantes nas políticas de assistência farmacêutica para ampliação do acesso, tanto para os usuários do setor público, quando do privado. Para citar alguns: a criação dos blocos de financiamento de assistência farmacêutica, com seus três componentes, hoje extintos; estratégias importantes, como a Farmácia Popular, Saúde Não Tem Preço, Aqui Tem Farmácia Popular, que ampliaram o acesso da população a um rol de medicamentos e produtos, que também têm sofrido recentemente retrocessos (CONASEMS, 2017); as melhorias no acesso a medicamentos de alto custo, a partir da expansão dos itens disponibilizados, bem como a aprovação da Lei no 12.880/2013 (BRASIL, 2013), que define a obrigatoriedade de cobertura obrigatória dos planos privados de assistência à saúde, em todo o território nacional, a tratamentos antineoplásicos de uso oral.

Tais políticas, entretanto, não necessariamente integraram a produção com o abastecimento ao público. Estudos recentes demonstraram, por exemplo, que o Programa Farmácia Popular, introduzido na agenda política de saúde brasileira em 2004, vinha adquirindo medicamentos a custos muito elevados, sugerindo a possibilidade de sua apropriação por interesses comerciais, como pode ser visto no estudo de Silva e Caetano ("Gastos com pagamentos no Programa Aqui Tem Farmácia Popular: evolução entre 2006-2014”, neste número.

Por outro lado, em termos do financiamento público de medicamentos, em 2011, a publicação da Lei no 12.401 (BRASIL, 2011) modificou a Lei no $8080 / 90$ (BRASIL, 1990), visando regulamentar o preceito constitucional da integralidade, estabeleceu uma nova "racionalidade" para a assistência terapêutica e a incorporação de novas tecnologias em saúde no âmbito do SUS. Essa regulamentação criou a 
Comissão Nacional de Incorporação de Tecnologias do SUS (CONITEC), com a função de assessorar o Ministério nas decisões relativas a incorporação, exclusão ou alteração de novos medicamentos, produtos e procedimentos, na constituição ou alteração de protocolos clínicos ou diretrizes terapêuticas, e nas atualizações da Relação Nacional de Medicamentos Essenciais. Sua criação fortaleceu a relação entre a avaliação de tecnologias em saúde e o desenvolvimento de política baseada em evidências, tornando-se uma arena importante também para as pressões e conflitos presentes na incorporação e financiamento público de insumos em saúde e medicamentos (CAETANO et al., 2017).

O conjunto de problemas acima elencados chama a atenção para a necessidade urgente de um olhar crítico e de um amplo debate na sociedade e na comunidade científica, visando subsidiar a elaboração e implantação de políticas industriais, comerciais e tecnológicas que criem condições para a diminuição das vulnerabilidades econômica e sanitária do país na área de medicamentos e tecnologias farmacêuticas.

Um conjunto de artigos presente nesse número da Physis explora alguns aspectos relativos às discussões brevemente travada acima, e cuja relevância e detalhamento estão bem destacados nos comentários de Jorge Bermudez, que abrem o tema.

\section{Referências}

BRASIL. Câmara dos Deputados. Comissão de Seguridade Social e Família. Relatório Final da Subcomissáo Especial de Desenvolvimento do Complexo Industrial em Saúde, Produção de Fármacos, Equipamentos e outros Insumos. Brasília: Câmara dos Deputados, 2011(a).

. Lei no 12.401, de 28 de abril de 2011. Altera a Lei no 8.080, de 19 de setembro de 1990, para dispor sobre a assistência terapêutica e a incorporação de tecnologia em saúde no âmbito do Sistema Único de Saúde. Diário Oficial [da] República Federativa do Brasil, Brasília, DF, abr. 2011 (b).

Lei no 12.880 , de 12 de novembro de 2013. Altera a Lei no 9.656, de 3 de junho de 1998, que "dispóe sobre os planos e seguros privados de assistência à saúde", para incluir tratamentos entre as coberturas obrigatórias. Diário Oficial [da] República Federativa do Brasil, Brasília, DF, nov. 2013.

. Lei no 8.080, de 19 de setembro de 1990. Dispóe sobre as condições para a promoção, proteção e recuperação da saúde, a organização e o funcionamento dos serviços correspondentes e dá outras providências. Diário Oficial [da] República Federativa do Brasil, Brasília, DF, 1990. . Lei no 9.279 de 14 de maio de 1996. Regula direitos e obrigaçóes relativos à propriedade industrial. Diário Oficial [da] República Federativa do Brasil, Brasília, DF, ago. 1998. 
. Lei no. 9.787 de 10 de fevereiro de 1999. Altera a Lei no 6.360 de 23 de setembro de 1976, que dispóe sobre a vigilância sanitária, estabelece o medicamento genérico, dispóe sobre a utilização de nomes genéricos em produtos farmacêuticos, e dá outras providências. Diário Oficial [da] República Federativa do Brasil, Brasília, DF, fev. 1999.

. Ministério da Saúde Portaria no 3.916, de 30 de outubro de 1998. Estabelece a Política Nacional de Medicamentos. Diário Oficial [da] República Federativa do Brasil, Brasília, DF, out. 1998.

. Ministério da Saúde. Secretaria de Ciência, Tecnologia e Insumos Estratégicos. Nota informativa: Abastecimento da penicilina benzatina 1.200.000 UI e espiramicina 1.500 .000 UI no país. Brasília, 2015. Disponível em: <http://www.soperj.org.br/novo/imageBank/ abastecimento-penicilina-benzatina.pdf>. Acesso em: 22 fev. 2017.

- Ministério da Saúde. Secretaria de Vigilância em Saúde. Departamento de DST, AIDS e Hepatites Virais. Nota Informativa $n^{\circ}$ 006/2016/GAB/DDAHV/MS. Informa a respeito da importância e urgência na aquisição de penicilina cristalina (ou potássica), tendo em vista que tal medicamento é tratamento padrão para diversas doenças com relevante impacto em saúde pública. Disponível em: http://www.aids.gov.br/sites/default/files/anexos/ legislacao/2016/58919/nota_informativa_no006_importancia_e_urgencia_na_a_82765.pdf; acesso em 08/12/2016.

CAETANO, R. et al. Incorporação de novos medicamentos pela Comissão Nacional de Incorporação de Tecnologias do SUS, 2012 a junho de 2016. Ciênc. saúde coletiva, v. 22, n 8 , p. 2513-2525, 2017.

COSTA, J.C.S. et al. Avaliação do setor produtivo farmoquímico no Brasil: capacitação tecnológica e produtiva. RECIIS - Rev Eletron de Comun Inf Inov Saúde, Rio de Janeiro, v. 8, n. 4, p. 443-460, dez. 2014.

INSTITUTO BRASILEIRO DE GEOGRAFIA E ESTATÍSTICA. Coordenação de Contas Nacionais. Conta-satélite de saúde: Brasil 2010-2015. Rio de Janeiro: IBGE, 2017, 79p.

INTERFARMA. Guia 2016. Disponível em: <http://www.interfarma.org.br/guia/guia_2016/ medicamentos_biologicos/>. Acesso em: 22 fev. 2017.

KORNIS, G.E.M. et al. Os marcos legais das políticas de medicamentos no Brasil contemporâneo (1990-2006). Rev. APS, Juiz de Fora, v. 11, n. 1, p. 85-99, mar. 2008.

MITIDIERI, T.L. et al. Há espaços competitivos para a indústria farmoquímica brasileira? Reflexôes e propostas para políticas públicas. Complexo Industrial da Saúde BNDES Setorial, Rio de Janeiro, v. 41, p 1-36, 2015. 